\title{
TerraSAR-X STARING SPOTLIGHT MONITORING OF A HIGHWAY BRIDGE IN THE CZECH REPUBLIC (PRELIMINARY RESULTS)
}

\author{
Ivana Hlaváčová ${ }^{(1)}$, Jan Kolomazník ${ }^{(2)}$, Lena Halounová ${ }^{(1)}$ \\ ${ }^{(1)}$ Czech Technical University, Thákurova 7, 16621 Praha 6, Czech Republic, Email:hlavacova@insar.cz \\ ${ }^{(2)}$ GISAT, s.r.o., Milady Horákové 57, 17000 Praha 7, Czech Republic, Email:jan.kolomaznik@gisat.cz
}

\begin{abstract}
Highway bridge in the southern part of Prague, Czech republic, is the longest bridge in the Czech republic and it is architectonically unique in Europe. It was built above the valley with confluence of two big rivers, Vltava and Berounka, in an area of frequent floods. On top, there is a five-lane highway with an important, circle-shape crossroad, and both ends of the bridge end up in a tunnel.

During construction, steel was partially replaced by concrete in comparison to the plan, and first cracks arose just after opening of the bridge in September 2010, and are progressively getting bigger.

We try to monitor this bridge using the InSAR technique with 22 TerraSAR-X scenes, acquired in the Staring Spotlight mode with a resolution of approximately 0.3 meters during June 2014 - February 2015 (11 days interval).
\end{abstract}

\section{INTRODUCTION}

The Radotín bridge (Radotínský most, Lahovická estakáda) was built as a part of the ring around the city of Prague, to connect the most utilized highways to Pilsen and to Brno. It is built above the confluence of Vltava and Berounka rivers, in an area of frequent floods.

In fact, the estacade is formed by two bridges, each of them built with different technology and by different company. The first one, with length of $236 \mathrm{~m}$, is on the eastern side: starts at the Komořany tunnel, runs under the ecoduct, above the Vltava river and ends at the large fly-over crossroad. The length of the western part, Lochkov Bridge (Lochkovský most) is $2045 \mathrm{~m}$, has 37 spans, crosses the lagoon, Berounka river and goes into the Lochkov tunnel. The bridge is made of steel and concrete and has unique construction based on oblique pillars. Maximum height of the estacade is $65 \mathrm{~m} \mathrm{[1].}$

Both parts of the estacade were built between 2006 and 2010. They were opened for cars and trucks in September 2010. Shortly after putting into operation microscopic cracks in welding of metal supportive construction emerged. Fissure has been monitored conventionally, however InSAR technique could bring complex image of the bridge behavior and indicate its potential deflection.

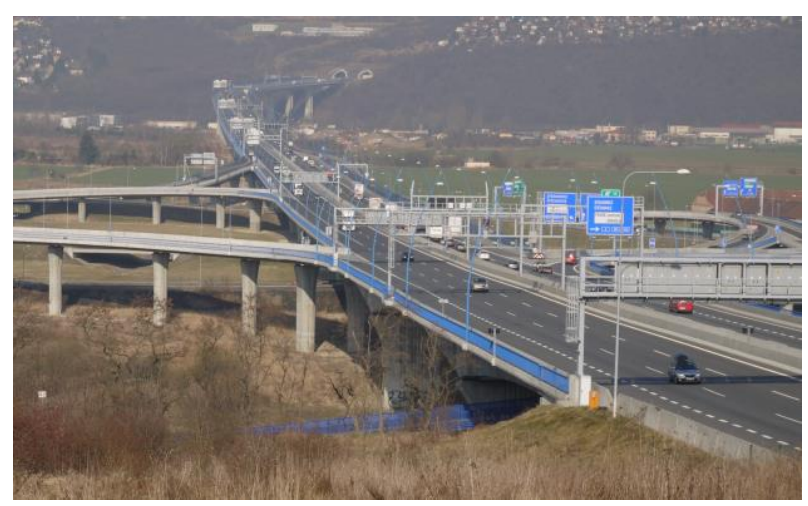

Figure 1. The area of interest (AOI)

\section{DATASET}

The estacade is monitored by the TerraSAR-X Staring Spotlight data with resolution of approximately $0.3 \mathrm{~m}$. Data are acquired from ascending track each 11 days, starting from June 2014, until April-May 2015. Up to now (February $\left.5^{\text {th }}, 2015\right)$, there are 22 scenes available, the total number is 33 .

As significant temperature effects are expected (high resolution, steel-concrete construction), the temperature is monitored at a nearby bridge (approx. $50 \mathrm{~m}$ away from the estacade). Unfortunately, up to now, the temperature is heavily dependent on the time (see figure 2 ), their covariance is -0.86 , therefore recognition of the linear deformation signal and the thermal dilation is not stable/possible. In addition, it is never certain that the deformation of the bridge is linear in time.

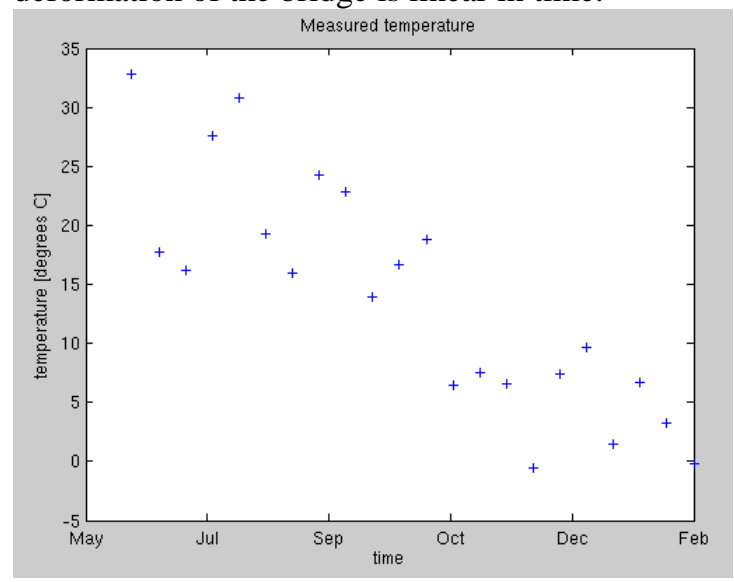

Figure 2. The measured temperature 
The bridge is monitored from the south and its orientation in the original SAR scene is approximately diagonal, i.e. both thermal dilation and deflection of the bridge can be monitored, however difficult to separate. The radar monitors only the top of the bridge, no pillars can be seen. The double-bounces are visible only at small parts of the bridge above the rivers.

\section{RESULTS, INTERPRETATION}

With 22 scenes, we are about to estimate the residual height of each points, its thermal dilation and deformation velocity. In addition, the thermal dilation and deformation velocity are expected to highly correlate, and therefore such a solution is expected to be unstable, i.e. the estimation can be different for two neighbouring points etc.

IPTA (Interferometric Point Target Analysis) as a part of the GAMMA software did not give reasonable results, probably due to a small number of scenes (in addition, we use an old version from 2008, where the thermal dilation estimation is not implemented).

Due to the high resolution a digital surface model (DSM) formed from laser scanning technique was used. Its irregular resolution was resampled to approx. $5 \times 5 \mathrm{~m}$ to be used by interferometric softwares. In addition, the DSM should be coregistered very precisely with the image. The perpendicular baseline to make the $2 \pi$ difference on $65 \mathrm{~m}$ height difference is approximately $70 \mathrm{~m}$, while the perpendicular baselines among the given data reach over $400 \mathrm{~m}$ in some cases.

For a preliminary analysis, we plotted several interferograms with short perpendicular baselines, where the height inaccuracy effects should not be visible (fig. 3). In this figure, only the part of the bridge around the crossroad is visible due to the fact that no phase changes are visible in the eastern part of the bridge.

Visually analysing the interferograms in figure 3, together with temporal and temperature baselines, it is obvious that the bridge suffers from a strong thermal dilation, but there are also other movements that cannot be attributed to temperature changes. These movements are visible in the interferograms made from images acquired in summer/autumn, however not in autumn/winter interferograms (see the last two interferograms in figure 3 , where the temperature difference is almost 0 ): there is some signal in one of them, but not in the other. Clearly, there is some deformation signal that is not linear in time. It can be permanent (movements due to cracks), or temporary (loading of the bridge). However, we cannot decide from these images.

Regular PS analysis was then performed in the SARproZ software with different requirements: estimation of thermal dilation only, of linear deformation only and of both together. In all cases, height corrections were also estimated.

Obviously, when estimating both linear deformation and thermal dilation, the achieved coherence was generally higher. However, the most reasonable results were found when estimating only the thermal dilations, and are presented here: figure 4 presents the estimated thermal dilation for the whole bridge, figure 5 presents time series for three marked points in figure 4.

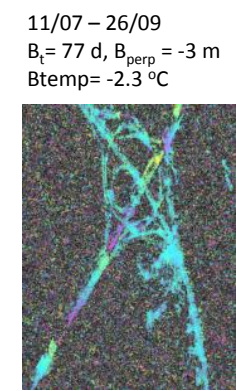

$09 / 11-01 / 12$

$B_{t}=22 d, B_{\text {perp }}=-6 m$

Btemp $=-8.0^{\circ} \mathrm{C}$

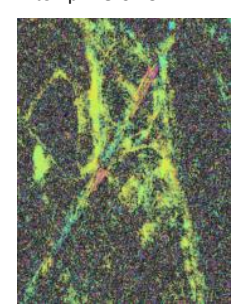

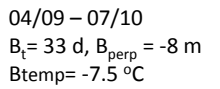

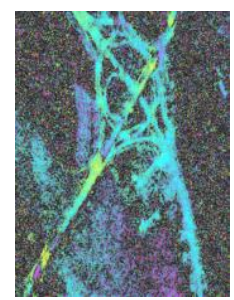

$12 / 12-14 / 01$

$B_{t}=33 d, B_{\text {perp }}=2 \mathrm{~m}$

Btemp $=-0.7^{\circ} \mathrm{C}$

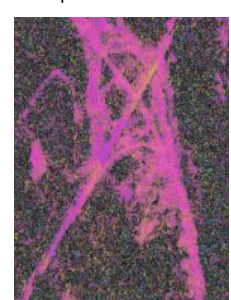

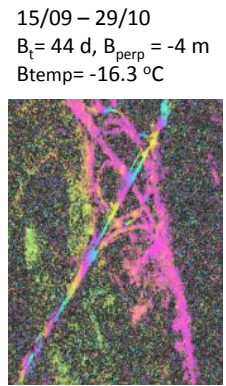

03/01-25/01

$B_{t}=22 d, B_{\text {perp }}=-7 \mathrm{~m}$

Btemp $=1.7^{\circ} \mathrm{C}$

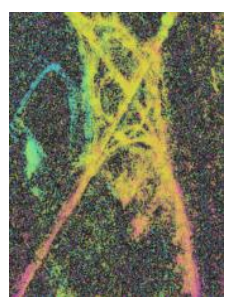

$15 / 09-12 / 12$

$\mathrm{B}_{\mathrm{t}}=88 \mathrm{~d}, \mathrm{~B}_{\text {perp }}=7 \mathrm{~m}$

Btemp $=-15.4^{\circ} \mathrm{C}$

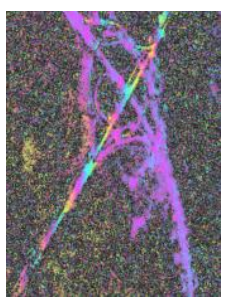

15/09-14/01

$B_{\mathrm{t}}=121 \mathrm{~d}, \mathrm{~B}_{\text {perp }}=9 \mathrm{~m}$

Btemp $=-16.1^{\circ} \mathrm{C}$

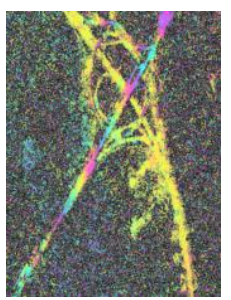

$18 / 10-12 / 12$

$\mathrm{B}_{\mathrm{t}}=55 \mathrm{~d}, \mathrm{~B}_{\text {perp }}=-6 \mathrm{~m}$

Btemp $=-11.4^{\circ} \mathrm{C}$

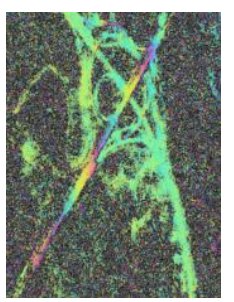

11/07-07/10

$\mathrm{Bt}=88 \mathrm{~d}$, Bperp $=13 \mathrm{~m}$

Btemp $=-0.2{ }^{\circ} \mathrm{C}$

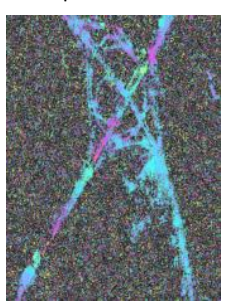

$18 / 10-14 / 01$

$\mathrm{B}_{\mathrm{t}}=88 \mathrm{~d}, \mathrm{~B}_{\text {perp }}=-5 \mathrm{~m}$ Btemp $=-12.1^{\circ} \mathrm{C}$

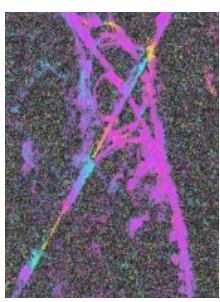

29/10 - 14/01

$\mathrm{B}_{\mathrm{t}}=77 \mathrm{~d}, \mathrm{~B}_{\text {perp }}=13 \mathrm{~m}$

Btemp $=0.2^{\circ} \mathrm{C}$

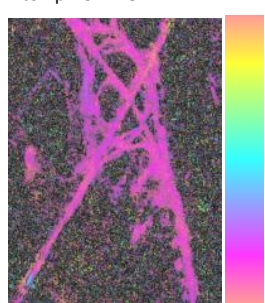

Figure 3. Interferograms (processed in GAMMA) with short perpendicular baselines, where the height errors should not be significant. Therefore, only the deformation and dilation signals are expected here. Only the crossroad is plotted as there is no interesting signal in the other part of the bridge. 


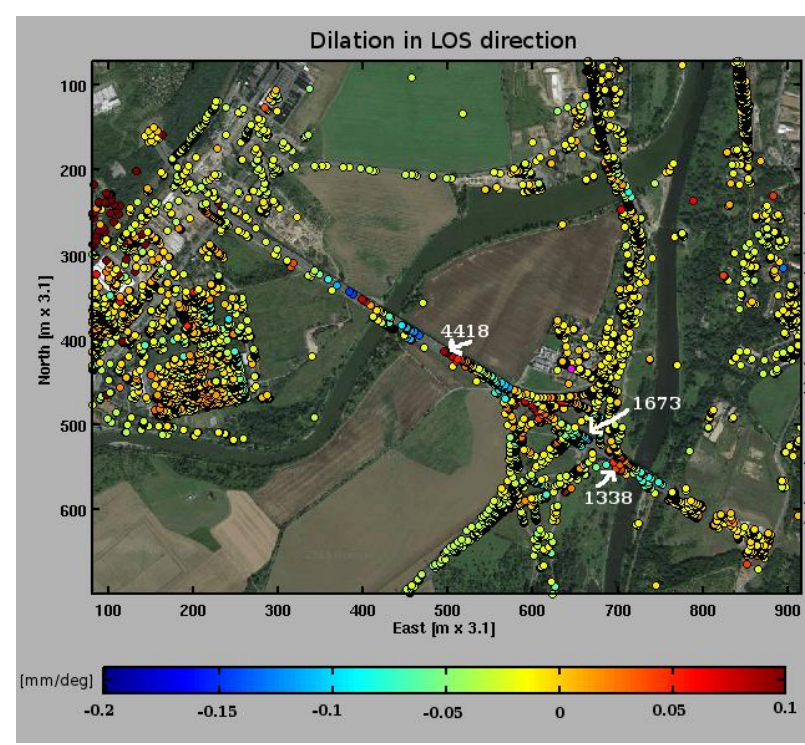

Figure 4. Estimated thermal dilation in LOS (by SarPROZ). Red (positive) values indicate the direction to the satellite, blue (negative) values indicate the direction away from the satellite. Reference point is marked in pink.

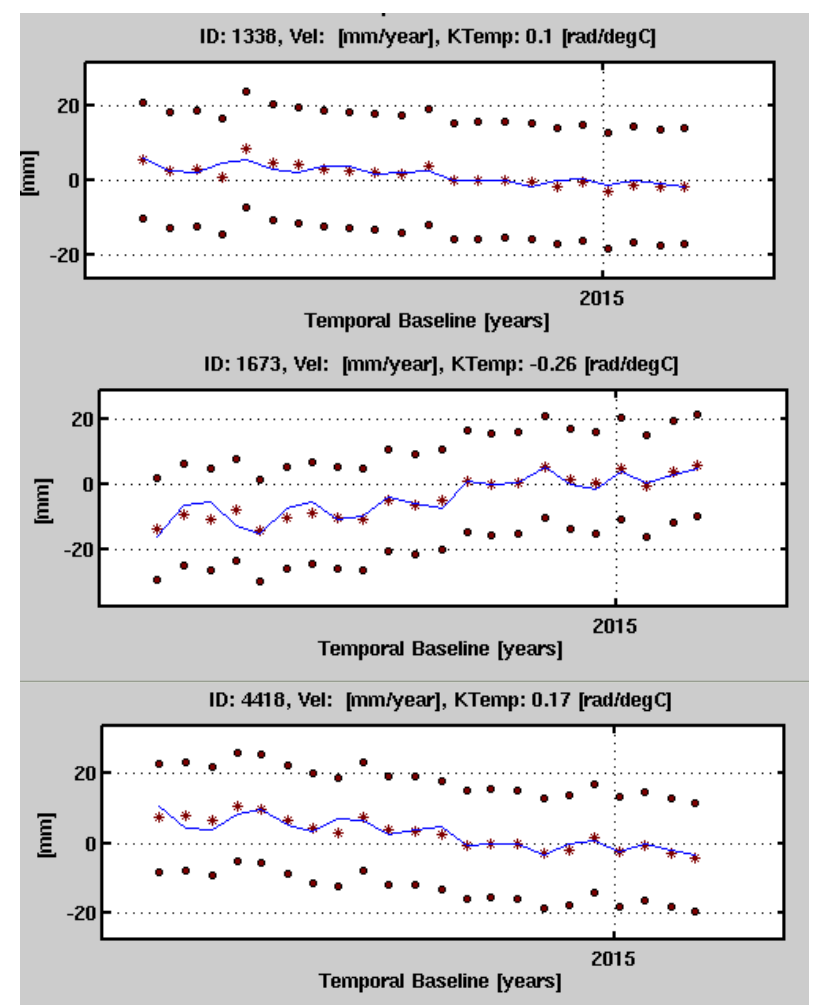

Figure 5. Time series (by SarPROZ) of the points marked in figure 4. Reference date is November $9^{\text {th }}$, 2014.

It is clear from figure 5, that the time series almost perfectly fits the thermal dilation model for the second half of the timeline (autumn/winter). On the other hand, residues for some summer (and the beginning of autumn) dates are significantly higher. However, it seems that the residue values are not gradually increasing or decreasing, so no real subsidence is expected here and the residues can be attributed either to atmospheric delay inhomogeneities, which are often found in Europe in summer [2] (even though the distance from the reference point is lower than $500 \mathrm{~m}$ ), or to bridge loading which is independent of the date of acquisition. It is also possible that the thermal dilation is nonlinear or the temperatures are not accurate enough (air temperature is used because some road temperature data are missing).

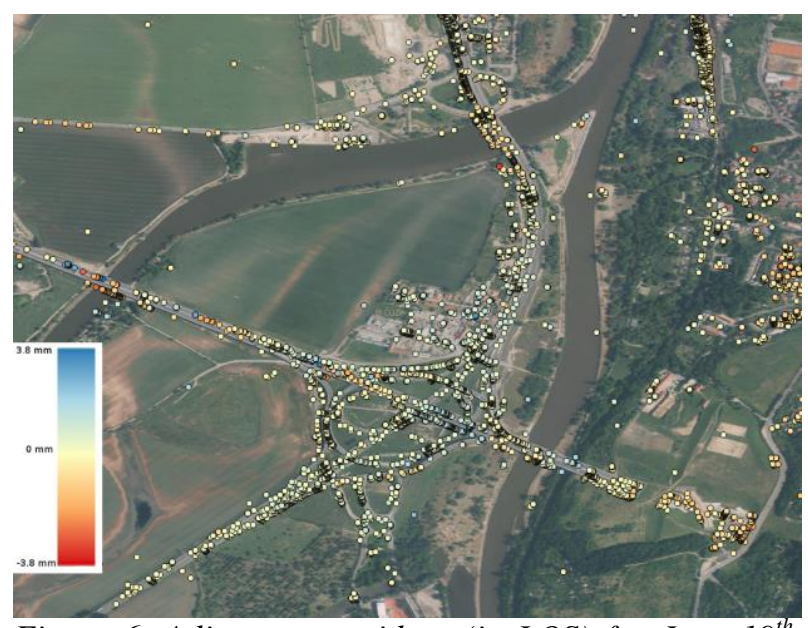

Figure 6. Adjustment residues (in LOS) for June $19^{\text {th }}$, 2014 (acquisition n. 1). Processed in SarPROZ.

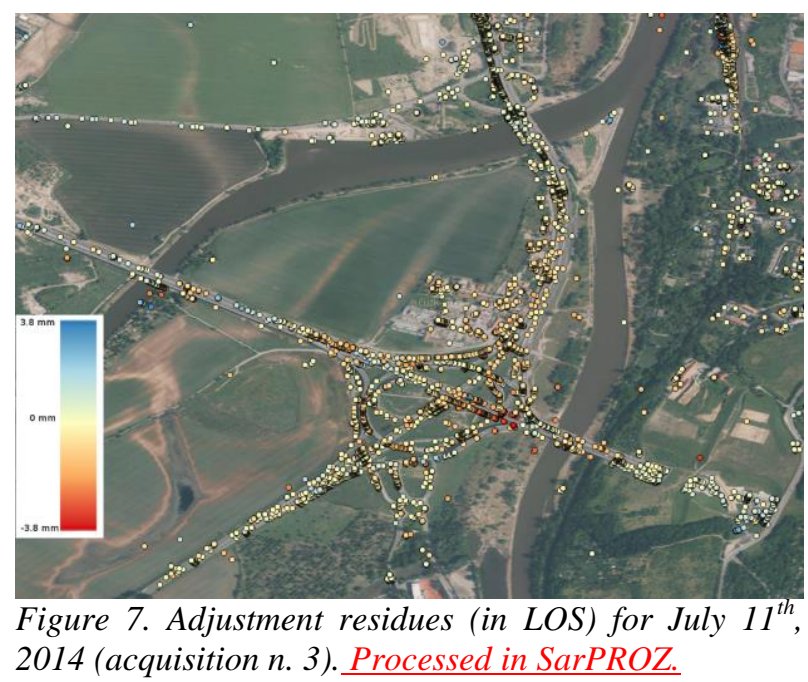

Please note that the red- and blue-coloured parts of the bridge alternate regularly, which is highly probably caused by the thermal dilation, and not by subsidence.

And it is important to note here, that some points are not displayed in figure 4 due to the lack of coherence, which can also be caused by some movements.

Unfortunately, from the processing view, it seems that the bridge "splits" into two above the Berounka river (the left one): if the reference point is selected on the western side, the coherence of the eastern side gets 


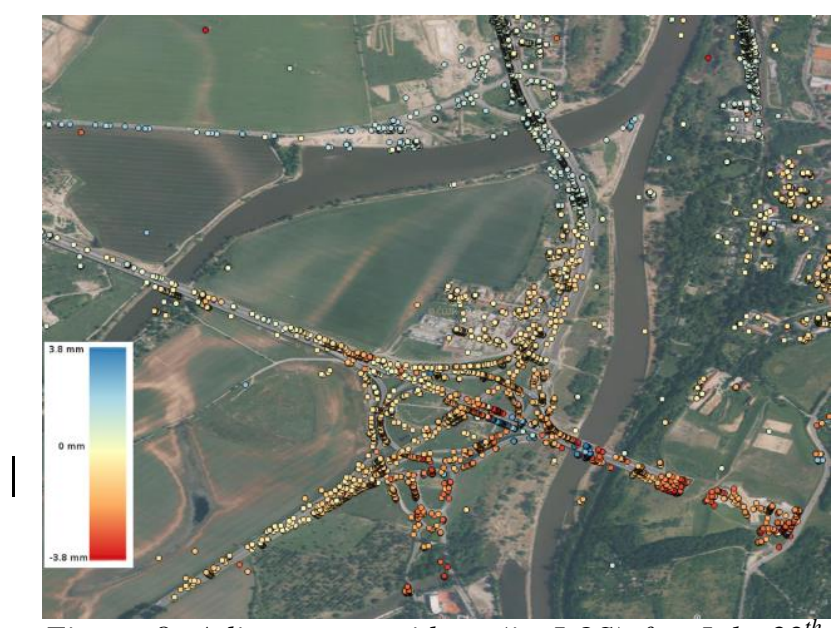

Figure 8. Adjustment residues (in LOS) for July 22 $2^{\text {th }}$, 2014 (acquisition n. 4). Processed in SarPROZ.

significantly worse, and if the reference point is selected on the eastern side (the case of fig. 4 and 5), the coherence of the points on the west is significantly lower. It seems that the bridge cannot be monitored as a whole, but each part will have to be monitored separately.

Figures 6, 7, 8 displays adjustment residues for few acquisition dates in space. Please note that the residues of the reference point are not zero (due to software) and the position of the reference point is the same as in figure 4. It is obvious in figures $6-8$, that the residues have a similar manner to the thermal dilation coefficient (displayed in figure 4), so it is possible that the thermal dilation is nonlinear w.r.t. temperature, or that the temperature measurements are not accurate enough.

\section{CONCLUSION}

The separation of the linear deformation and thermal dilation signals is ambiguous and sensitive to noise now due to the fact that the temporal and temperature baselines are not really independent. We hope that the situation will get better with the final number of 33 scenes, acquiring throughout almost the whole year | (June - April/May).

However, it seems that the major signal in this area is the thermal dilation. The rest of the signal (residues) can be attributed either to atmospheric delay inhomogeneity, or some non-linear deformations, caused possibly by cracks in the construction, but more probably by nonlinear thermal dilation or by bridge loading, which cannot be evaluated.

On the other hand, it is possible that a (small) area subject to gradual subsidence was excluded due to lower coherence.

\section{REFERENCES}

1. Radotínský most, Wikipedia. http://cs.wikipedia.org/wiki/Radotinsky most

2. Schaeffer, M., Hannemann, W.: Atmospheric phase shift identification for individual dates based on multi-reference DInSAR or PSI data. In Proceedings of the ESA Living Planet Symposium, 2010.

\section{Acknowledgements}

The project was supported by the project no. TB0100MD021 Beta „Zhodnocení využitelnosti dat dálkového průzkumu Země pro použití v dopravě" from the Technology Agency of the Czech republic.

The processing was performed in the SARproZ and GAMMA softwares.

Data for the project was provided by DLR (project LAN 2379. 